\title{
Wnt signaling in atherosclerosis
}

Citation for published version (APA):

Blankesteijn, W. M., \& Hermans, K. C. M. (2015). Wnt signaling in atherosclerosis. European Journal of Pharmacology, 763, 122-130. https://doi.org/10.1016/j.ejphar.2015.05.023

Document status and date:

Published: 15/09/2015

DOI:

10.1016/j.ejphar.2015.05.023

Document Version:

Publisher's PDF, also known as Version of record

\section{Document license:}

Taverne

\section{Please check the document version of this publication:}

- A submitted manuscript is the version of the article upon submission and before peer-review. There can be important differences between the submitted version and the official published version of record.

People interested in the research are advised to contact the author for the final version of the publication, or visit the DOI to the publisher's website.

- The final author version and the galley proof are versions of the publication after peer review.

- The final published version features the final layout of the paper including the volume, issue and page numbers.

Link to publication

\footnotetext{
General rights rights.

- You may freely distribute the URL identifying the publication in the public portal. please follow below link for the End User Agreement:

www.umlib.nl/taverne-license

Take down policy

If you believe that this document breaches copyright please contact us at:

repository@maastrichtuniversity.nl

providing details and we will investigate your claim.
}

Copyright and moral rights for the publications made accessible in the public portal are retained by the authors and/or other copyright owners and it is a condition of accessing publications that users recognise and abide by the legal requirements associated with these

- Users may download and print one copy of any publication from the public portal for the purpose of private study or research.

- You may not further distribute the material or use it for any profit-making activity or commercial gain

If the publication is distributed under the terms of Article $25 \mathrm{fa}$ of the Dutch Copyright Act, indicated by the "Taverne" license above, 


\title{
Wnt signaling in atherosclerosis
}

\author{
W. Matthijs Blankesteijn*, Kevin C.M. Hermans \\ Department of Pharmacology and Toxicology, Cardiovascular Research Institute Maastricht, Maastricht University, P.O. Box 616, 6200MD Maastricht, The \\ Netherlands
}

\section{A R T I C L E I N F O}

\section{Article history:}

Received 17 March 2015

Accepted 1 May 2015

Available online 15 May 2015

\section{Keywords:}

Wnt

Frizzled

Signal transduction

Atherosclerosis

Myocardial infarction

Stroke

\begin{abstract}
A B S T R A C T
Atherosclerosis is a disease of the vascular wall that forms the basis for a large spectrum of pathologies of various organs and tissues. Although massive research efforts in the last decades have yielded valuable information about its underlying molecular mechanisms, this has not led to a translation into effective therapeutic interventions that can stop the progression or even can induce regression of atherosclerosis. This underscores the importance of investigations on the involvement of novel signaling pathways in the development and progression of this condition. In this review we focus on the role of Wnt signaling in atherosclerosis. Experimental evidence is presented that Wnt signaling is involved in many aspects of the development and progression of vascular lesions including endothelial dysfunction, macrophage activation and the proliferation and migration of vascular smooth muscle cells. Subsequently, we will discuss the role of Wnt signaling in myocardial infarction and stroke, two common pathologies resulting from the progression of atherosclerotic lesions towards an unstable phenotype. Despite the fact that the published data sometimes are ambiguous or even conflicting, a picture is emerging that an attenuation of Wnt signaling is beneficial for the cardiovascular system that is compromised by atherosclerosis.
\end{abstract}

(c) 2015 Elsevier B.V. All rights reserved.

\section{Introduction}

Atherosclerosis is a disease of the arterial wall that forms the pathological basis for a broad array of cardiovascular conditions such as ischemia, myocardial infarction (MI) and stroke. The vascular lesions start to develop in the second decade of life (Freedman et al., 1988), but usually become clinically relevant in middle-aged and elderly persons. The disease is characterized by a progressive thickening of the intima where inflammatory cells, lipids and extracellular matrix accumulate. This can either lead to narrowing of the artery, as e.g. observed in angina pectoris, or to an acute thrombotic occlusion of the affected artery when the lesion ruptures.

Several risk factors contribute to the development of

\footnotetext{
Abbreviations: ABCA1, ATP binding cassette transporter A1; APC, adenomatous polyposis coli; CAD, coronary artery disease; CAMKII, calmodulin dependent protein kinase II; CK1, casein kinase 1; COX, cyclooxygenase; CRD, cysteine-rich domain; DKK, Dickkopf; EC, endothelial cell; ELISA, enzyme-linked immunosorbent assay; GSK3 $\beta$, glycogen synthase kinase $3 \beta$; IGFBP3, Insulin-Like Growth Factor Binding Protein 3; HUVEC, human umbilical vein endothelial cells; I $\kappa$ B, Inhibitor of nuclear factor kappa B; IL, Interleukin; JNK, Jun N-terminal kinase; LDL, low density lipoprotein; LRP, lipoprotein receptor-like protein; NF- $\kappa B$, nuclear factor kappa B; PKC, protein kinase C; TCF-LEF, T-cell factor- lymphoid enhancing factor; VSMC, vascular smooth muscle cell; WIF, Wnt inhibitory factor

* Corresponding author.

E-mail address: wm.blankesteijn@maastrichtuniversity.nl (W. Matthijs Blankesteijn).
}

atherosclerotic plaques. Originally, elevated plasma lipids-more in particular LDL cholesterol-were considered to be the main risk factors for atherosclerosis development. Extensive epidemiological studies have learned that this relationship is far more complex (McNamara, 2000). Interestingly, this observation is supported by the ever increasing number of pleiotropic effects that have been reported for statins, the main class of therapeutic agents for atherosclerosis. Originally developed as lipid lowering drugs, these agents turned out to have multiple effects on the vasculature, the anti-inflammatory effect probably being a prominent contributor to the therapeutic success of these agents (Liao and Laufs, 2005). This underscores the importance of a better understanding of the molecular mechanisms involved in atherosclerosis development and progression, which can subsequently be translated into improved therapy.

In this review, we will focus on the role of Wnt signaling in atherosclerosis. After an introduction and a brief description of this signaling pathway, we will present experimental evidence for its involvement in many aspects of the development and progression of an atherosclerotic lesion, including endothelial dysfunction, macrophage differentiation and smooth muscle cell migration. We will subsequently present data on its involvement in cardiac ischemia and stroke. We will finish with a discussion on the potential of this pathway as a therapeutic target in cardiovascular diseases. 


\section{A brief overview of Wnt signaling and its constituents}

Wnt proteins form a large family of excreted signaling molecules that are present in virtually all animals. The first Wnt protein was discovered in developing Drosophila and called 'wingless' to describe the phenotype when the gene was inactive. Around the same time, a proto-oncogene named Int- 1 was identified in mice that turned out to be a mammalian homologue of Wingless; therefore the names were combined into Wnt. In the meantime, 19 members of the Wnt family have been identified in mammals, with an average size of 350-400 amino acids and a strongly conserved pattern of 22-24 cysteines. Moreover, palmitoylation of a Serine residue was found to be indispensable for biological activity of the protein (Miller, 2002).

Wnt proteins can interact with multiple classes of receptors. Frizzled proteins, a family of seven transmembrane receptors, were the first to be identified as receptors for Wnt ligands (Schulte and Bryja, 2007). A general characteristic of frizzled proteins is the well-conserved extracellular cysteine-rich domain (CRD). The crystal structure of a Wnt-CRD complex (Janda et al., 2012) revealed that the shape of Wnt proteins mimics the palm of a hand, grabbing the Fizzled CRD with two extensions referred to as the thumb and index finger. Lipoprotein receptor-related proteins 5 and 6 (LRP5 and 6) act as co-receptors in the complex (Cong et al., 2004). Furthermore, the tyrosine kinase receptor families Ror and Ryk can act as receptors for several Wnts as well (Kikuchi, 2000).

Modulation of Wnt signaling has been described by several classes of endogenous proteins, but in the context of this review the soluble Frizzled-related proteins (sFRP) and proteins from the Dickkopf family (DKK) are the most relevant. sFRPs contain a CRD with structural similarity to that of frizzled proteins. Binding of
Wnt to sFRPs scavenges Wnts in the extracellular space so these proteins can act as functional Wnt antagonists (Surana et al., 2014). However, sFRPs have also been shown to have Wnt-independent mechanisms of action, e.g. via induction of bone morphogenetic proteins (BMPs) (Ostrom, 2014). Proteins from the DKK family interact with the co-receptors LRP5 and 6, thereby preventing the formation of the ligand-receptor complex and inducing a rapid internalization of the LRP (Cruciat and Niehrs, 2013).

Multiple signaling pathways have been identified for Wnt. The most extensively studied pathway is the $\mathrm{Wnt} / \beta$-catenin pathway, also referred to as 'canonical' Wnt signaling (Fig. 1). When this pathway is inactive, the second messenger $\beta$-catenin is continuously phosphorylated by a so-called destruction complex consisting of Dishevelled, GSK3 $\beta$, Axin, APC and Casein kinase-1. This phosphorylation of $\beta$-catenin is the first step towards its degradation. Activation of Wnt signaling causes the destruction complex to disintegrate, resulting in cytoplasmic accumulation of $\beta$-catenin. This $\beta$-catenin can move towards the nucleus to interact with transcription factors from the T-cell factor / leucocyte enhancer factor (TCF/LEF) family to activate transcription of Wntresponsive genes.

Non-canonical signaling of Wnt proteins can take place via multiple pathways, but the best characterized are the planar cell polarity pathway, involving Rho/c-jun N-terminal kinase (JNK) signaling, and the Wnt $/ \mathrm{Ca}^{2+}$ pathway (Fig. 2). The former pathway is involved in pattern formation during embryonic development via a direct activation of the small G-proteins Rac and Rho by dishevelled. The Wnt $/ \mathrm{Ca}^{2+}$ pathway involves G-protein mediated activation of phospholipase $\mathrm{C}$, causing $\mathrm{Ca}^{2+}$ release from intracellular stores. This in its turn can activate $\mathrm{Ca}^{2+}$-dependent enzymes such as protein kinase $\mathrm{C}$, calcium/calmodulin-dependent kinase II and calcineurin (Angers and Moon, 2009; Dijksterhuis

\section{Canonical Wnt/Frizzled Signaling}

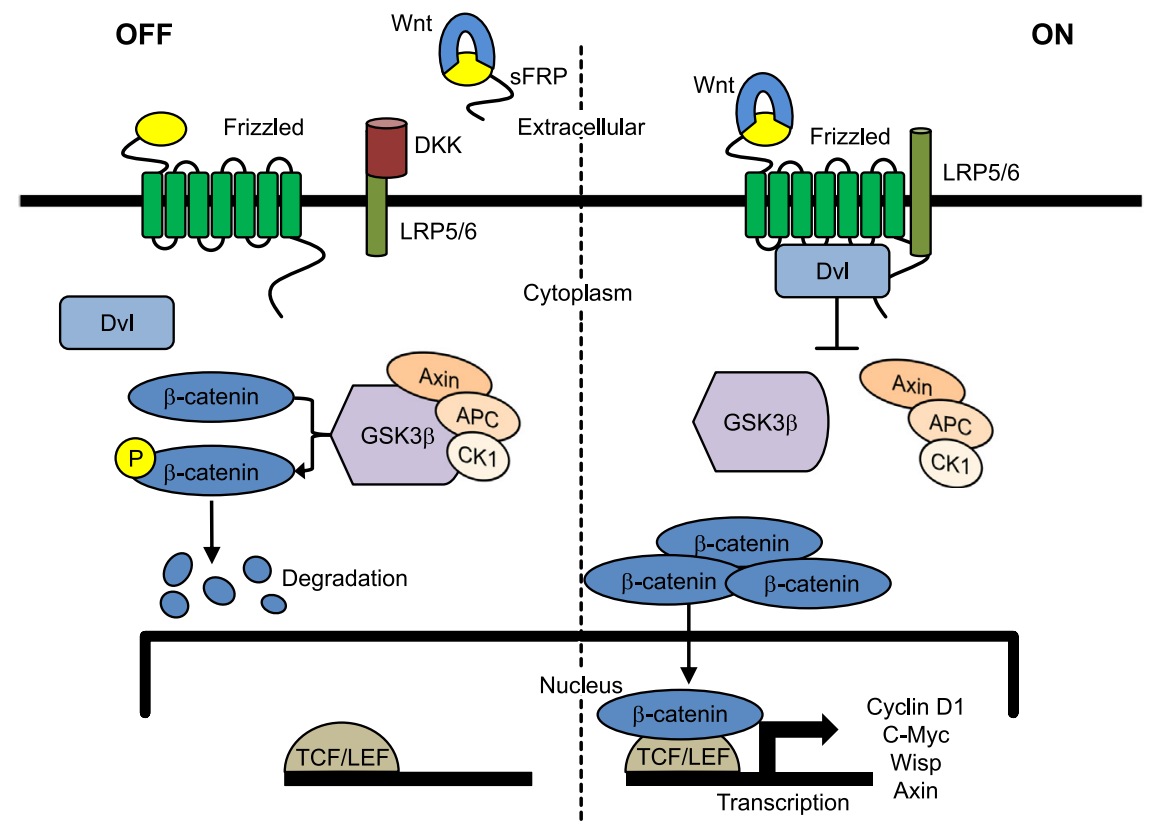

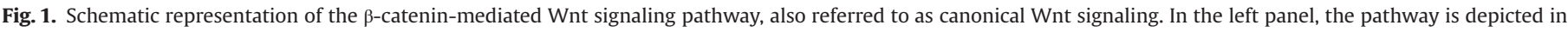

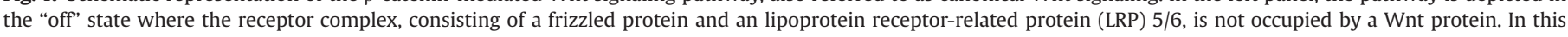

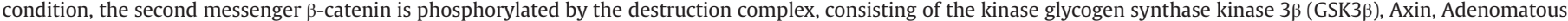

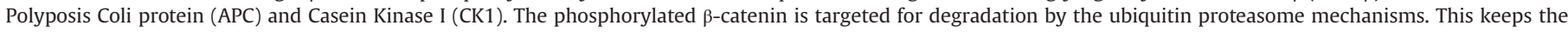

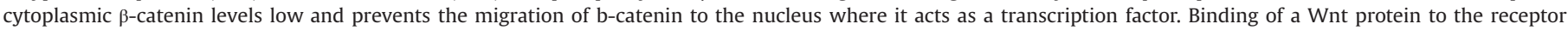

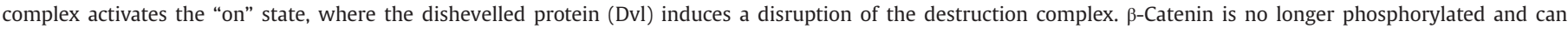

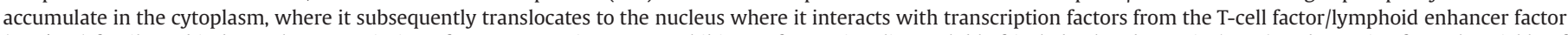

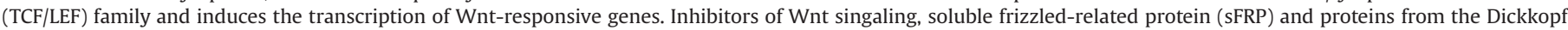
family (DKK) are also depicted. 


\section{Non-canonical Wnt/Frizzled signaling}

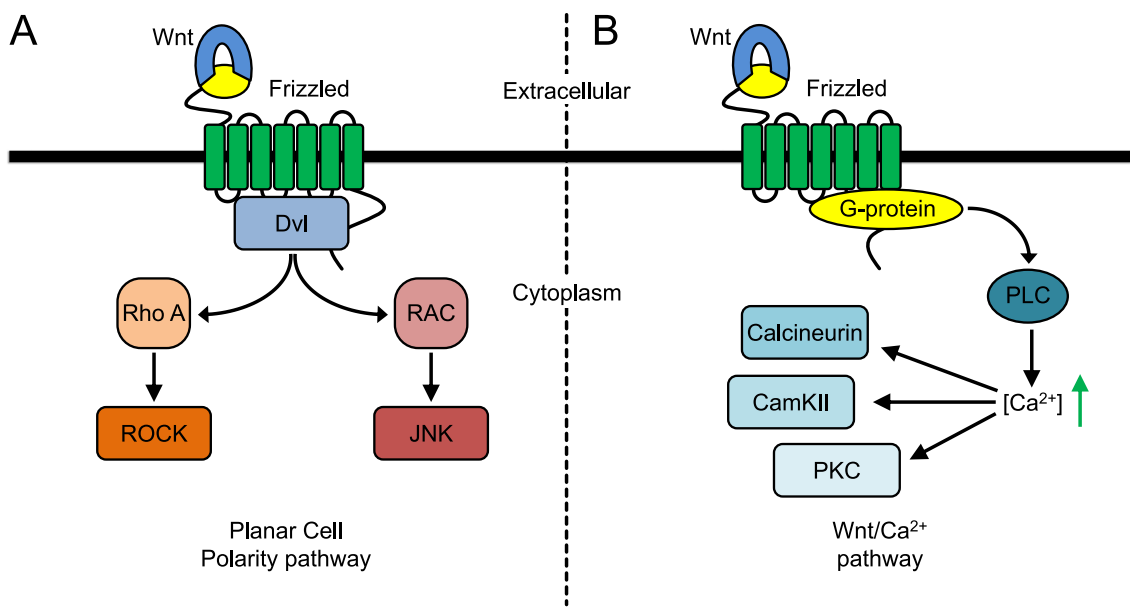

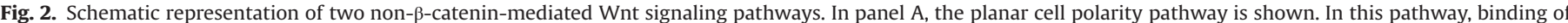

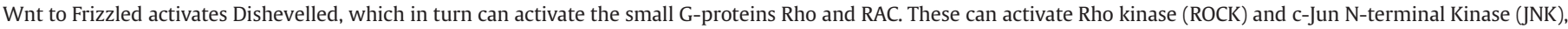

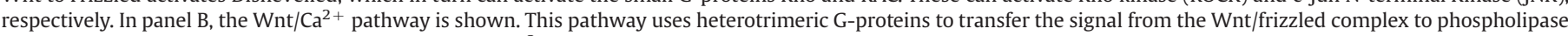

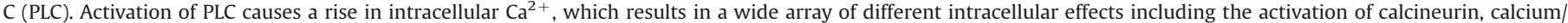
calmodulin dependent kinase II (CAMKII) and protein kinase C (PKC).

\section{et al., 2014).}

Wnt signaling plays an essential role in many developmental processes such as tissue patterning, specification of cell fate and control of asymmetric cell division. The involvement of Wnt signaling in cardiogenesis and vasculogenesis has been studied extensively and is described in several excellent reviews (Dejana, 2010; Gessert and Kuhl, 2010). However, it is beyond the scope of the present review to discuss this topic in detail.

\section{Wnt signaling in atherosclerotic plaques}

A first step in the pathogenesis of atherosclerosis is dysfunction of the endothelial cells that form the inner lining of arteries and arterioles, allowing adhesion of monocytes and their permeation into the subintimal space. There the monocytes differentiate into macrophages, which release diverse cytokines. This triggers the migration of smooth muscle cells from the media to the intima. Both macrophages and smooth muscle cells accumulate lipids and an atherosclerotic plaque is formed that has a fibrous cap on the luminal side of the artery. Rupture of the fibrous cap causes the contents of the plaque to be released in the lumen, resulting in the formation of a thrombus that can occlude the artery (Libby, 2002).

\subsection{Clinical observations}

A first indication of the involvement of Wnt signaling in atherosclerosis stems from the description of an Iranian family with autosomal dominant early coronary artery disease, hypertension, hyperlipidemia and osteoporosis. In this family, a homozygous mutation that introduces a missense mutation, $\mathrm{R} 611 \mathrm{C}$, in the LDL receptor-related protein (LRP)6 gene could be linked to the affected subjects (Mani et al., 2007). In the meantime, a more common variant of LRP6, I1062V, has been identified that is related to an increased risk for carotid artery atherosclerosis in hypertensive patients. In patients with this LRP6 variant, the levels of LRP6 expression in carotid atherosclerotic plaques were significantly reduced, but in contrast to the R611C variant the blood lipid levels were not affected (Sarzani et al., 2011). Because LRP6 acts as a co-receptor in the canonical Wnt signaling, these findings are suggestive for a role of this pathway in atherosclerosis.

Several researchers have investigated the relation between
Wnt expression and the severity and stability of atherosclerotic lesions. Christman et al. (2008) reported predominant Wnt5a staining of intimal areas of macrophage accumulation in atherosclerotic lesions of apolipoprotein-deficient mice and human endarterectomy samples. This finding was confirmed in other studies from this group where a correlation between Wnt5a expression and severity of the atherosclerotic lesion was demonstrated (Bhatt et al., 2012; Malgor et al., 2014). In these studies, the expression of Wnt5a in human monocyte-derived macrophages and THP-1 cells could be induced by ox-LDL whereas native LDL was inactive. On the other hand, Wnt5a reduced the accumulation of cholesterol in lipid-loaded cells by regulating the mRNA expression of Caveolin-1 and ATP binding cassette transporter A1 (ABCA1), both being involved in reverse cholesterol transport. This may present a novel mechanism of Wnt5a-mediated cholesterol transportation in macrophages and VSMC (Qin et al., 2014). Antagonists of Wnt signaling, in particular DKK1, were also detected in advanced and unstable atherosclerotic lesions. Immunohistochemical staining revealed platelet aggregates in thrombus material derived from the site of plaque rupture as an important source of DKK1 (Ueland et al., 2009). For more information on the role of Wnt5a in atherosclerosis, we refer to a recent review by Bhatt and Malgor (2014).

Components of Wnt signaling not only have been detected in the atherosclerotic lesions, but can also be detected in the circulation. Elevated levels of Wnt5a were reported in about half of the atherosclerotic subjects, whereas in the other half the levels were similar to healthy control subjects (Malgor et al., 2014). Similarly, elevated levels of DKK1 were reported in plasma obtained from patients with carotid atherosclerosis (Ueland et al., 2009), acute MI (Perez Castrillon et al., 2010) and acute ischemic stroke (SeifertHeld et al., 2011). Moreover, DKK1 levels were reported to correlate with coronary atherosclerosis and calcification scores (Kim et al., 2011) and to be an independent predictor of adverse cardiac events (Wang et al., 2013). In a cohort of young MI patients (age $<40$ years), the levels of Wnt 1 and DKK1 were determined at 3 days and one year after the ischemic event. Wnt1 levels were significantly lower compared to age-matched controls at 3 days post-MI and stayed stable over time, whereas elevated DKK1 levels were only detected at the late time point (Goliasch et al., 2012). These studies indicate that components of activated Wnt signaling pathways spill over from the diseased tissues into the circulation 
where they can be monitored by minimally invasive procedures.

\subsection{Wnt signaling in endothelial dysfunction}

ECs form the boundary between the circulating blood and the underlying tissue. When exposed to laminar blood flow, ECs play an important role in the hemodynamic regulation by releasing vasoactive mediators, like e.g. nitric oxide. To this end, ECs can sense both mechanical and chemical signals. Lesions of the endothelium can occur at sites in the circulation where the blood flow is disturbed, e.g. at the branching point of arteries. In damaged endothelial cells, the expression of inflammatory and prothrombotic genes is induced, resulting in the recruitment of inflammatory cells to the subendothelial layer. This process, generally referred to as endothelial dysfunction, is one of the hallmarks in the development of atherosclerosis (Heusch et al., 2014).

In several studies, the role of Wnt signaling in endothelial cell function has been investigated. Working with mouse brain microvascular ECs and HUVEC, Wright et al. reported the expression of several members from the Wnt an Fzd families. Moreover, they observed a Wnt1-induced increase in the free pool of $\beta$-catenin and a concomitant activation of a T-cell factor/leucocyte enhancer factor (TCF/LEF)-dependent reporter construct, indicative of activation of $\beta$-catenin dependent Wnt signaling. Overexpression of Wnt1, but not Wnt5a, induced proliferation of the cultured endothelial cells (Goodwin et al., 2007; Wright et al., 1999). However, later studies yielded opposite results by showing augmented EC proliferation by Wnt5a/Ca ${ }^{2+}$-mediated signaling and inhibition of EC proliferation by canonical (Wnt1-induced) Wnt signaling (Cheng et al., 2003, 2008; Masckauchan et al., 2006). A full screening of the expression of all Wnts, Fzds, LRP5/6, DKKs and sFRPS was performed by Goodwin et al. (2006) in ECs from different origins. Although some Wnts (Wnt2b, 4 and 5a) and Fzds (Fzd6 and 8) were detected in all samples, a considerable variability in expression profiles was reported for the other members, particularly in HUVEC from different sources. Stabilization of cytoplasmic $\beta$-catenin and activation of reporter gene expression was more pronounced in subconfluent than in confluent EC. The large variation in expression patterns between different sources of ECs and the effects of cell-cell contact may help to explain the inconsistent results reported in the literature regarding this subject.

As indicated above, endothelial dysfunction and inflammation are essential events in the early development of atherosclerosis. Interestingly, Wnts not only can modulate the proliferation of ECs but also play a role in the regulation of endothelial inflammation. Kim et al. showed that a $1 \mathrm{~h}$ incubation of ECs with recombinant Wnt5a induced the expression of cytokines like IL- $1 \alpha$, IL- 6 and IL8, and inflammatory genes like COX2 (Kim et al., 2010). Pulsatile exposure to Wnt5a enhanced this expression even further. The authors propose a cooperative activation of inflammatory genes by Tumor necrosis factor- $\alpha$ and Wnt5a, the former activating NFKB via IKK activation and the latter activating NFKB via the $\mathrm{Ca}^{2+} / \mathrm{PKC}$ signaling route.

In a recent study, the role of the redox regulatory protein $\mathrm{p} 66^{\text {shc }}$ in $\beta$-catenin mediated Wnt signaling was studied in HUVEC. Wnt3a induced a rapid JNK-mediated phosphorylation of $p 66^{\text {shc }}$ at Ser36, which could be inhibited by DKK1. Knockdown of p66 $66^{\text {shc }}$ attenuated $\beta$-catenin mediated gene transcription. Active $\beta$-catenin reduced the endothelium-mediated relaxation of mouse aorta rings via an increase of reactive oxygen species. The authors concluded that $\mathrm{p} 66^{\text {shc }}$ plays a vital role in the Wnt3a-mediated endothelial dysfunction (Vikram et al., 2014). These studies underscore that components of Wnt signaling are not only expressed in vascular endothelial cells, but that activation of Wnt signaling contributes to endothelial dysfunction.

\subsection{Wnt signaling in macrophages}

Atherosclerosis is currently regarded as an inflammatory disease in which macrophages play a crucial role. Monocytes binding to areas of dysfunctional endothelium subsequently migrate to the subendothelial space where they differentiate into macrophages. There they are loaded with lipids to form the foam cells that are characteristic for atheromatous lesions. Moreover, macrophages can release matrix-degrading enzymes which can weaken the fibrous cap that forms over the lesion, giving rise to plaque rupture and acute atherotrombotic events (Libby, 2002).

The observation that macrophage-rich areas of atherosclerotic plaques contain high levels of Wnt 5a (Christman et al., 2008) was the starting point for research on the role of Wnts in the macrophage activation. The expression of Wnt5a in human macrophages can be induced by bacterial structures, involving TLR4 (Pereira et al., 2009), but also by oxidized LDL (Bhatt et al., 2012). Via interaction with Fzd5, this Wnt5a can induce the expression of proinflammatory cytokines, thereby contributing to the development of the inflammatory response. On the other hand, Wnt3a has an anti-inflammatory effect via suppression of GSK3 $\beta$, which in turn can regulate the NFKB-dependent gene transcription (Schaale et al., 2011).

The role of LRP5 in macrophage differentiation and migration upon lipid loading was investigated by Borrell-Pages et al. LRP5 transcription was induced by aggregated LDL (agLDL). Silencing of LRP5 by siRNA treatment reduced the accumulation of lipids in the macrophages and the motility of macrophages in a wound healing assay and significantly reduced LDL uptake in the macrophages. The authors conclude that LRP5 plays a role in the innate inflammatory response to lipid infiltration (Borrell-Pages et al., 2011).

The same authors tested the role of LRP5 in vivo using LRP5deficient mice fed a high cholesterol diet. Compared to wildtypes, these mice had mildly elevated total cholesterol levels and developed larger atherosclerotic plaques, indicating that LRP5 has a protective effect on atherosclerosis development (Borrell-Pages et al., 2014). These results are in agreement with the previously published observations from (Magoori et al., 2003), who showed $\sim 3$-fold greater atherosclerotic lesions with extensive foam cell accumulation and destruction of the internal elastic lamina in apoE;LRP5 double knockout mice compared to apoE knockouts at 6 month of age.

\subsection{Wnt signaling in vascular smooth muscle cells}

Migration of vascular smooth muscle cells (VSMC) from the media towards the intima is one of the hallmarks in the development of an atherosclerotic plaque. Quiescent VSMC are activated by a complex mechanism, probably involving the inflammatory mediators released from atherosclerotic lesion, which results in proliferation and migration. This is accompanied by a switch from a contractile towards a synthetic phenotype, characterized by increased production of cytokines and extracellular matrix and a reduction in contractile proteins (Owens et al., 2004).

Several studies have shown a stimulating effect of $\beta$-catenin on VSMC proliferation. This second messenger of Wnt signaling induces the upregulation of pro-proliferative genes like cyclin D1 (Quasnichka et al., 2006; Wang et al., 2002) via the transcription factor TCF4. The activation of this pathway was observed in balloon denudation of the carotid artery in several studies (Slater et al., 2004; Uglow et al., 2003). Applying carotid ligation in TOPgal (Wnt reporter gene) transgenic mice, Tsaousi et al. recently demonstrated that $\beta$-catenin-mediated signaling was activated both in the media and intima at 3 and 28 days after the intervention (Tsaousi et al., 2011b). 
$\beta$-Catenin not only resides in a free form in the cytoplasm, but can also be sequestered at the plasma membrane in a complex with other catenins and cadherins, where it plays a role in cell-cell adhesion. Disruption of the cell adhesion complexes liberates $\beta$ catenin that can be transported to the nucleus where it can activate VSMC proliferation via cyclin D1 expression (Slater et al., 2004; Uglow et al., 2003). This mechanism may be helpful in explaining the proliferation of VSMCs when they are liberated from the media and migrate to the intima.

In several studies the question was addressed which Wnts are involved in VSMC proliferation. Both Wnt 1 and Wnt3a have been shown to induce canonical Wnt signaling and cyclin D expression in VSMCs (Marchand et al., 2011). Inhibition of Wnt signaling using a dominant negative form of LRP6 was shown to attenuate VSMC proliferation (Wang et al., 2004). Interestingly, Wnt4 has recently been identified as an endogenous activator of VSMC proliferation. Platelet-derived growth factor BB-induced VSMC proliferation could be inhibited by specific knockdown of Wnt 4 and intimal thickening after carotid artery ligation was inhibited in mice heterozygous for Wnt4 or by adding Wnt inhibitory factor (WIF1) (Tsaousi et al., 2011a). Inhibition of Wnt signaling via the overexpression of sFPR1 also resulted in inhibition of VSMC proliferation both in vitro and in vivo (Ezan et al., 2004). The combined results underscore the importance of a functional Wnt receptor complex in the regulation of VSMC proliferation.

As indicated in the description of the signaling pathways in this review, a crucial step in the canonical Wnt signaling is the inactivation of the kinase activity of GSK3 $\beta$ by disassembly of the $\beta$ catenin destruction complex. However, phosphorylation of GSK3 $\beta$ at the $\operatorname{Ser}^{9}$ residue by Akt can also inactivate the enzyme, leading to nuclear $\beta$-catenin accumulation (van de Schans et al., 2008). This mechanism was found to be responsible for the IL-18- induced proliferation of human saphenous vein VSMCs. This effect was attributed to IL-18-mediated signaling via PI3kinase, Akt, GSk3 $\beta, \beta$-catenin, TCF/LEF and Wnt inducible signaling protein (WISP)-1 (Reddy et al., 2011).

Apart from its role in $\beta$-catenin phosphorylation, GSK3 $\beta$ also plays a role in the control of Nuclear Factor of activated T-Cells (NFAT) signaling. In inactive cells, NFAT resides in the cytoplasm in a hyperphosphorylated form; GSK3 $\beta$ is one of the kinases responsible for its phosphorylation. An increased intracellular $\mathrm{Ca}^{2+}$ concentration activates the phosphatase calcineurin. This enzyme dephosphorylates NFAT and promotes its nuclear translocation, resulting in an induction of proliferation and migration of VSMCs (Chow et al., 2008).

\subsection{Wnt signaling in vascular calcification}

Wnt signaling plays an important role in bone development and remodeling (Wang et al., 2014). Because bone formation has similarities with vascular calcification, a role for Wnt signaling in this process can be anticipated. The expression of Wnt ligands can be activated in vascular endothelial cells and myofibroblasts, where oxidized LDL and Tumor necrosis factor- $\alpha$ can induce the expression of Bone Morphogenetic Protein-2 which in turn activates the transcription factor MSX2 (Marinou et al., 2012). In conclusion, there is growing evidence that Wnt signaling is involved in multiple aspects of the formation of atherosclerotic lesions. Up till now, studies tend to focus on a single component of Wnt signaling rather than adopting a more integrated approach. This may help to explain some of the inconsistencies between the different studies.

\section{Wnt signaling in pathologies resulting from atherosclerosis}

\subsection{Wnt signaling in the response to myocardial infarction}

MI is the result of an acute thrombotic occlusion of a coronary artery, affecting the cardiac muscle that depends on this artery for its supply of oxygen and nutrients. Although it is current medical practice to reduce the damage by reopening the affected coronary artery by Percutaneous Coronary Intervention (PCI), there is still a fair amount of patients with significant injury of the heart for different reasons: patients report to their doctor too late or with atypical symptoms, a particular problem in women (Maas et al. 2011); The PCI procedure is not entirely successful, e.g. due to the no-reflow phenomenon (Galasso et al., 2014); on a global scale, only a minority of MI patients has access to this technologically advanced and costly procedure. Therefore it is important to study the process of infarct healing and to identify new therapeutic targets that can be exploited in the treatment of this condition.

\subsubsection{The different phases of infarct healing}

The process of infarct healing has been extensively described in reviews from our group (Cleutjens et al., 1999; Daskalopoulos et al., 2012; van den Borne et al., 2010) and others (Shinde and Frangogiannis, 2014; Sun et al., 2002). Briefly, the wound healing after MI takes several months to complete and consists of 4 phases. The first phase is characterized by the cardiomyocyte death resulting from the ischemia. This cell death typically peaks at $6-$ $8 \mathrm{~h}$ after the onset of the ischemia and can either be the result of necrosis or apoptosis. The death of the cardiomyocyte evokes an inflammatory response starting at $12-16 \mathrm{~h}$ post-infarction, representing the second phase of infarct healing. This phase is characterized by the initial invasion of the infarct area with polymorphonuclear neutrophils (PMNs). These cells can clear the cellular debris from the infarct area by phagocytosis and degrade the pre-existing matrix by releasing MMPs. The invasion of PMNs is followed by a second wave of invading monocytes that differentiate into macrophages, typically peaking at 3-4 days after infarction. The inflammatory cells release a broad spectrum of chemokines and cytokines, initiating the formation of granulation tissue which forms the third phase of the wound healing. This phase typically starts at around 1 week post-MI and is complete after 1-2 months. In this phase new blood vessels are formed and fibroblasts enter the infarct area where they can differentiate into myofibroblasts. The latter cell type not only can produce and deposit extracellular matrix but also has contractile properties, allowing the granulation tissue to stay compact by continuous contraction. The fourth phase of infarct healing is characterized by the maturation of the granulation tissue into a scar. This process is characterized by a reorganization of the blood vessels, an increased deposition of extracellular matrix and a gradual reduction in the number of myofibroblasts. However, as cardiac scars are exposed to repetitive stretching due to the cardiac cycle, the presence of myofibroblasts in the infarct are appears to be beneficial as these cells can play a role in the replacement of damaged extracellular matrix fibers.

\subsubsection{Expression of Wht components in the infarcted heart}

It is now almost two decades ago that our group reported the upregulated expression of Fzd1 and -2 proteins during the wound healing process after MI. Using in situ hybridization, we could demonstrate the migration of Frizzled-expressing cells from the border zone to the center of the infarct during the course of the wound healing. This was suggestive for an expression of these receptors on (myo)fibroblasts, which could be confirmed by staining of adjacent sections with $\alpha$-smooth muscle actin ( $\alpha \mathrm{SMA}$ ) immunohistochemistry (Blankesteijn et al., 1997). 
In the meantime, the time course of the expression of different components of the Wnt/frizzled signaling cascade has been studied quite extensively by different research groups. The general pattern that emerges is that the expression gradually increases during the first week after MI, reaching a plateau at $\sim 1$ week and then gradually decreases towards levels observed in sham animals. Barandon et al. determined the expression levels of most of the Wnt and Frizzled proteins in 1 week-old mouse infarcts. From all the Wnts tested Wnt10B expression was elevated and Wnt7B expression reduced. These authors observed the upregulation of Fzd1, 2, 5 and 10 and the downregulation of Fzd8 in the infarct area, whereas Fzd3, 4, 6 and 7 were not altered. This was accompanied by an abundant expression of sFRP1 at day 7, whereas the expression levels of this gene returned to baseline at day 15 post-MI (Barandon et al., 2003). The elevated expression of Wnt10B was confirmed by Aisagbonhi et al. at 5 days post-MI, although these authors also report the upregulation of Wnt2, -4 and -11 (Aisagbonhi et al., 2011). The expression pattern of Dvl1, studied in male rats, showed a gradual increase until 7 days postMI, followed by a decline to baseline values at 28 days post-MI. In this study, in situ hybridization and immunohistochemical techniques were used to demonstrate that Dvl1 was expressed in migrating myofibroblasts and endothelial and smooth muscle cells of newly formed blood vessels in and around the infarct area at 4 and 7 days post-MI (Chen et al., 2004).

\subsubsection{Activation of Wnt signaling after myocardial infarction studied} by using reporter mice

An alternative way of demonstrating activation of canonical Wnt signaling is the use of reporter mice. Using the Axin2-LacZ reporter mouse, Oerlemans et al. observed an activation of canonical Wnt signaling in Sca+ progenitor cells, endothelial cells, c-Kit + cells, monocytes and fibroblasts in both the border zone and areas remote from the infarct, starting at 1 week after infarction and gradually increasing at 2 and 3 weeks post-MI. The authors conclude that canonical Wnt signaling is activated upon cardiac ischemia in a wide variety of cell types throughout the heart (Oerlemans et al., 2010). These observations were mostly confirmed using TOPGAL mice, harboring a LacZ gene under the control of three tandem $\beta$-catenin responsive consensus TCF/LEF binding motifs. In non-infarcted control mice, canonical Wnt signaling was only observed in the valves and the walls of the large blood vessels at the base of the heart. Permanent coronary artery occlusion, however, induced a massive increase in LacZ expression starting at day 4 post-MI and reaching its maximum during the formation of granulation tissue at 7 days postMI. The activated canonical Wnt signaling was mainly observed in endothelial cells and $\alpha$-SMA positive mesenchymal cells. Cell lineage tracing experiments revealed that the latter cell type was formed as a result of endothelial-to-mesenchymal transition. In vitro experiments confirmed that activation of canonical Wnt signaling in endothelial cells induces mesenchymal transition, suggesting that the myofibroblasts in the infarct area are from endothelial origin (Aisagbonhi et al., 2011). This endothelial-to-mesenchymal transition was recently confirmed by Duan et al., who observed Wnt1-dependent canonical Wnt signaling in the epicardial cells at 5 days after ischemia/reperfusion in mice. This activation of canonical Wnt signaling was found to be crucial for epicardial expansion and endothelial-to-mesenchymal transition in the epicardium, as demonstrated by epicardial-specific deletion of $\beta$-catenin (Duan et al., 2012).

\subsubsection{Effect of interventions at the level of the receptor complex on infarct healing}

In several studies, the role of Wnt signaling in infarct healing has been assessed by targeting the pathway at different levels. The administration of compounds that target components of the frizzled receptor complex has been shown to be effective in modulating the wound healing response. Oikonomopoulos et al. injected recombinant Wnt3a protein into the border zone of the infarct area immediately after induction of MI. At 1 week post-MI, they observed an increased infarct size, reduced LV septal thickness, increased LV diastolic volume and attenuated fractional shortening. The authors conclude that this adverse effect of Wnt3a on cardiac remodeling was due to a reduction in the number of cardiac side population cells via an insulin-like growth factor binding protein 3 (IGFBP3)-mediated mechanism, leading to an attenuated generation of new cardiomyocytes around the infarct area (Oikonomopoulos et al., 2011). Applying a similar intracardial injection strategy, Min et al. (2011) reported a beneficial effect of DKK2 administration on infarct healing in a rat cardiac ischemia/ reperfusion model, reflected by a higher fractional shortening over controls. This treatment resulted in a reduced infarct size and fibrosis, less apoptosis and an increased microvessel count in the infarct area. The pro-angiogenic effect of DKK2 was confirmed in in vitro angiogenesis experiments. Interestingly, DKK1 showed opposing effects in these experiments, but injections of DKK1 in the infarct area were not reported. Results from our research group confirm the beneficial effects of interventions at the level of the receptor complex. Systemic administration of a peptide fragment of Wnt5a, named UM206, for 2 and 5 weeks via osmotic minipumps reduced infarct size and improved cardiac function in a mouse model of MI as determined by echocardiography and $\mathrm{dP} / \mathrm{dt}$ measurements. This could be attributed to a reduction in infarct size and increased myofibroblast numbers in the infarct area (Laeremans et al., 2011). Taken together, these studies suggest that inhibition of Wnt signaling is beneficial after MI, although the underlying molecular mechanisms that were reported are diverse and probably reflect the involvement of Wnt signaling in many different aspects of infarct healing.

\subsubsection{Targeting Wnt signaling by modulating sFRPs}

Modulation of sFRP levels, a family of 5 endogenous Wnt scavenging proteins, has been employed in several studies. Overexpression of FrzA, the bovine equivalent of sFRP1, was shown to have a beneficial effect on cardiac function after permanent coronary artery ligation and cryoinjury and to prevent infarct rupture. This was the result of a reduction in infarct size and a thickening of the infarct area in the FrzA transgenic animals. These beneficial effects could be attributed to an attenuation of the apoptotic response and increased angiogenesis and collagen deposition in the infarct area (Barandon et al., 2003). The authors could demonstrate that the beneficial effect of FrzA overexpression was the result of a reduced neutrophil activation and recruitment to the scar, using a model of bone marrow transplantation from transgenic mice overexpressing FrzA (Barandon et al., 2011). Similar results have been reported for SFRP4. Injection of this protein into the cardiac muscle showed a reduced scar size, accompanied with a thicker wall and less deterioration of cardiac function compared to control (Matsushima et al., 2010). From these studies, it can be concluded that an attenuation of the activation of Wnt signaling in the infarcted myocardium proves to be beneficial for the wound healing process and for cardiac function post-MI.

Regarding sFRP2, the results are more ambiguous. On the one hand, Kobayashi et al. (2009) reported an increase in sFRP2 expression till 7 days after MI followed by a decline at day 14 postMI. In sFRP2-null mice subjected to MI, the authors showed reduced fibrosis and a significantly improved cardiac function. On the other hand, overexpression of sFRP2 has also been shown to have beneficial effects on infarct healing. Building on a previous study where they observed beneficial effects of injecting mesenchymal stem cells overexpressing Akt, Mirotsou et al. (2007) injected conditioned medium from these stem cells, shown to overexpress sFRP2 up to 100 -fold, into the border zone of the 
infarct. This exogenously administered sFRP2 could antagonize the pro-apoptotic Wnt3a produced by ischemic cardiomyocytes, resulting in smaller infarcts and subsequently improved cardiac function. Administration of recombinant sFRP2 protein, but not sFRP1 or -3, yielded similar results (He et al., 2010). The ambiguous results for sFRP2 may be explained by non-Wnt mediated inhibition of Bone Morphogenetic Protein (BMP)-1 and on collagen processing (Mastri et al., 2014).

\subsubsection{Interventions at the level of the $\beta$-catenin degradation complex}

Another intervention more downstream in the Wnt signaling pathway that has frequently been employed is targeting the $\beta$ catenin destruction complex, more in particular GSK3 $\beta$. Woulfe et al. (2010) reported a reduced LV dilatation and an improved cardiac function in mice with an inducible cardiomyocyte-specific deletion of GSK3 $\beta$ at 8 weeks post-MI. This could be attributed to augmented hypertrophy and increased proliferation of cardiomyocytes around the infarct area GSK3 $\beta$-deficient mice. Improved infarct healing was also observed after injection of mesenchymal stem cells that overexpress GSK3 $\beta$ in the border zone just after coronary artery ligation. Overexpression of GSK3 $\beta$ not only increased the survival of these stem cells but also had positive effects on cardiomyocyte differentiation, an upregulation of cardiac progenitor cells in the infarct area and increased angiogenesis (Cho et al., 2011). The apparent discrepancy between these two studies may be attributed to the different cell types that were targeted, underscoring once more the involvement of Wnt signaling in many pathways, sometimes with opposite effects.

A drug-mediated intervention at the level of the destruction complex was reported by Saraswati et al. (2010). In this study Pyrvinium was used, an anti-helminthic agent with potent inhibitory effects on canonical Wnt signaling that acts via Casein Kinase I $\alpha$. Injecting this compound in the border zone at the time of infarction was shown to attenuate LV dilatation at 30 days postMI. However, this did not result in reduced infarct size or improved cardiac function.

In several studies the effect of targeting of the downstream second messenger of canonical Wnt signaling, $\beta$-catenin, on infarct healing has been addressed. Hahn et al. showed that overexpression of a constitutively active variant of $\beta$-catenin in cardiomyocytes and cardiac fibroblasts decreased apoptosis of these cells, induced hypertrophy of cardiomyocytes and increased the cell number of fibroblasts and their differentiation into myofibroblasts. When injected into the border zone of the infarct in rats, infarct size was significantly reduced, apoptosis was diminished and the cell cycle was activated in both cell types (Hahn et al., 2006). Using $\alpha$ MHC-dependent overexpression or depletion of the $\beta$-catenin expression, the opposite effect of $\beta$-catenin on infarct healing was reported by (Zelarayan et al., 2008). Interestingly, these authors report the presence of increased numbers of small cardiomyocytes in the subepi- and subendocardial layer of the $\beta$ catenin depleted mice and demonstrated that these cardiomyocytes were derived from cardiac progenitor cells. Inhibition of the transcription activation of $\beta$-catenin by administering the compound ICG-001 also showed an improved infarct healing by promoting epithelial-to-mesenchymal transition in epicardial cells (Sasaki et al., 2013). This is again in contrast with the previously mentioned study by Duan et al., showing that activation of $\beta$-catenin mediated Wnt signaling augments the epithelial-to-mesenchymal transition in epicardial cells (Duan et al., 2012). These contradictive results may be explained by the differences in experimental approach and the different cell types that were targeted.

Taken together, Wnt signaling has been shown to be involved in many aspects of infarct healing. The discrepancies between the outcomes some of the studies may point to the importance of correct timing and targeting of the interventions in order to achieve beneficial effects.

\subsection{Wnt signaling in stroke}

Over the last years, experimental evidence has accumulated that Wnt signaling is involved in ischemic brain injury. By permanent endothelin-1 induced occlusion of the middle cerebral artery in rats, Mastroiacovo et al. (2009) observed the rapid induction of the Wnt antagonist DKK1 in the ischemic regions of the brain, whereas $\beta$-catenin levels were found to be increased. In the Doubleridge mouse model, characterized by lower levels of DKK1 expression, the same procedure resulted in reduced cerebral damage compared to wildtypes during the follow-up of 1 week. Inhibition of GSK3 $\beta$ with $\mathrm{LiCl}$ rescued the phenotype of the Doubleridge mice. Using transient occlusion of the middle cerebral artery, the ischemic brain damage in mice haploinsufficient for LRP6 was investigated (Abe et al., 2013). These authors observed larger infarct volumes and more severe motor deficits in the LRP6 $^{+/-}$group compared to wildtype at 3 days after ischemia. Although LRP6 is part of the canonical Wnt signaling pathway, these effects could be attributed to an alteration in the balance between activating and inhibitory phosphorylation of GSK3 $\beta$, leading to an increased GSK3 $\beta$ activity and mitochondrial dysfunction, rather than an accumulation of $\beta$-catenin. The mitochondrial dysfunction could be reversed by administration of a GSK3 $\beta$ inhibitor. Interestingly, a similar role of GSK3 $\beta$ has been described in cardiac ischemic preconditioning, suggesting a common mechanism (Juhaszova et al., 2004).

Although activation of Wnt signaling appears to be detrimental in the first days after brain ischemia, activation of Wnt signaling may be beneficial on the long run. Overexpression of Wnt3a in the striatum by lentiviral injection, 5 days before endothelin- 1 induced ischemic brain damage of that area significantly enhanced functional recovery after ischemic injury after a follow-up of 4 weeks. This was accompanied by an increased number of BrdUpositive cells that differentiated into mature neurons in the ischemic striatum by day 28 . These data indicate that activation of Wnt signaling can induce neurogenesis from neural stem cells. Interestingly, in a recent study from Sun et al. (2014), intragastric administration of morroniside, extracted from the fruits of Cornis officinalis, was shown to promote neurogenesis via activation of Wnt/ $\beta$-catenin signaling in a rat model of focal brain ischemia via transient occlusion of the middle cerebral artery. Taken together, these results underscore that Wnt signaling is involved in both beneficial and detrimental processes in brain ischemia. Therefore, potential interventions will need to be tailored and timed to augment the former and inhibit the latter processes.

\section{Conclusions}

In the last decades, our knowledge on Wnt signaling has broadened from its involvement in development towards its role in multiple disease processes. Mutations in components of Wnt signaling are tightly associated with the development and progression of different forms of cancer, but in cardiovascular diseases such associations are rare. In contrast, cardiovascular diseases, including atherosclerosis and its consequences, are mostly characterized by an upregulation of Wnt signaling due to an increased production and interaction of its components. As described in this review, a frequently observed pattern is that the body-in an attempt to control its cardiovascular physiology - responds to an insult by an overshoot in Wnt signaling activation. Therefore, interventions aiming at an inhibition of Wnt signaling are in most cases beneficial for cardiovascular function, although this is not a 
general finding and the results are ambiguous in some cases. Because Wnt signaling, with its multiple components and signaling pathways, is very complex it is too early to tell whether it will be applicable as a therapeutic target for cardiovascular diseases in the future. Its involvement in multiple cellular and pathological processes of atherosclerosis and its consequences, however, makes it a promising and fascinating subject of further study to better understand the critical control mechanisms of cardiovascular homeostasis in health and disease.

\section{Acknowlegements}

\section{K.C.M. Hermans is funded by the Dutch Heart Foundation (2010B196)}

\section{References}

Abe, T., Zhou, P., Jackman, K., Capone, C., Casolla, B., Hochrainer, K., et al., 2013. Lipoprotein receptor-related protein-6 protects the brain from ischemic injury. Stroke 44 (8), 2284-2291.

Aisagbonhi, O., Rai, M., Ryzhov, S., Atria, N., Feoktistov, I., Hatzopoulos, A.K., 2011 Experimental myocardial infarction triggers canonical Wnt signaling and endothelial-to-mesenchymal transition. Dis. Model. Mech. 4 (4), 469-483.

Angers, S., Moon, R.T., 2009. Proximal events in Wnt signal transduction. Nat. Rev. Mol. Cell Biol. 10 (7), 468-477.

Barandon, L., Casassus, F., Leroux, L., Moreau, C., Allieres, C., Lamaziere, J.M., et al., 2011. Secreted frizzled-related protein-1 improves postinfarction scar formation through a modulation of inflammatory response. Arterioscler. Thromb. Vasc. Biol. 31 (11), e80-e87.

Barandon, L., Couffinhal, T., Ezan, J., Dufourcq, P., Costet, P., Alzieu, P., et al., 2003. Reduction of infarct size and prevention of cardiac rupture in transgenic mice overexpressing FrzA. Circulation 108 (18), 2282-2289.

Bhatt, P.M., Lewis, C.J., House, D.L., Keller, C.M., Kohn, L.D., Silver, M.J., et al., 2012 Increased Wnt5a mRNA Expression in Advanced Atherosclerotic Lesions, and Oxidized LDL Treated Human Monocyte-Derived Macrophages. Open Circ. Vasc. J. $5,1-7$.

Bhatt, P.M., Malgor, R., 2014. Wnt5a: a player in the pathogenesis of atherosclerosis and other inflammatory disorders. Atherosclerosis 237 (1), 155-162.

Blankesteijn, W.M., Essers-Janssen, Y.P., Verluyten, M.J., Daemen, M.J., Smits, J.F., 1997. A homologue of Drosophila tissue polarity gene frizzled is expressed in migrating myofibroblasts in the infarcted rat heart. Nat. Med. 3 (5), 541-544.

Borrell-Pages, M., Romero, J.C., Badimon, L., 2014. Cholesterol modulates LRP5 expression in the vessel wall. Atherosclerosis 235 (2), 363-370.

Borrell-Pages, M., Romero, J.C., Juan-Babot, O., Badimon, L., 2011. Wnt pathway activation, cell migration, and lipid uptake is regulated by low-density lipoprotein receptor-related protein 5 in human macrophages. Eur. Heart J. 32 (22), 2841-2850.

Chen, L., Wu, Q., Guo, F., Xia, B., Zuo, J., 2004. Expression of Dishevelled-1 in wound healing after acute myocardial infarction: possible involvement in myofibroblast proliferation and migration. J. Cell Mol. Med. 8 (2), 257-264.

Cheng, C.W., Smith, S.K., Charnock-Jones, D.S., 2003. Wnt-1 signaling inhibits human umbilical vein endothelial cell proliferation and alters cell morphology. Exp. Cell Res. 291 (2), 415-425.

Cheng, C.W., Yeh, J.C., Fan, T.P., Smith, S.K., Charnock-Jones, D.S., 2008. Wnt5amediated non-canonical Wnt signalling regulates human endothelial cell proliferation and migration. Biochem. Biophys. Res. Commun. 365 (2), 285-290.

Cho, J., Zhai, P., Maejima, Y., Sadoshima, J., 2011. Myocardial injection with GSK3beta-overexpressing bone marrow-derived mesenchymal stem cells attenuates cardiac dysfunction after myocardial infarction. Circ. Res. 108 (4), 478-489.

Chow, W., Hou, G., Bendeck, M.P., 2008. Glycogen synthase kinase 3beta regulation of nuclear factor of activated T-cells isoform $\mathrm{c} 1$ in the vascular smooth muscle cell response to injury. Exp. Cell Res. 314 (16), 2919-2929.

Christman 2nd, M.A., Goetz, D.J., Dickerson, E., McCall, K.D., Lewis, C.J., Benencia, F. et al., 2008. Wnt5a is expressed in murine and human atherosclerotic lesions. Am. J. Physiol. Heart Circ. Physiol. 294 (6), H2864-H2870.

Cleutjens, J.P., Blankesteijn, W.M., Daemen, M.J., Smits, J.F., 1999. The infarcted myocardium: simply dead tissue, or a lively target for therapeutic interventions. Cardiovasc. Res. 44 (2), 232-241.

Cong, F., Schweizer, L., Varmus, H., 2004. Wnt signals across the plasma membrane to activate the beta-catenin pathway by forming oligomers containing its receptors, Frizzled and LRP. Development 131 (20), 5103-5115.

Cruciat, C.M., Niehrs, C., 2013. Secreted and transmembrane wnt inhibitors and activators. Cold Spring Harb. Perspect. Biol. 5 (3), a015081.

Daskalopoulos, E.P., Janssen, B.J., Blankesteijn, W.M., 2012. Myofibroblasts in the infarct area: concepts and challenges. Microsc. Microanal. Off. J. Microsc. Soc. Am. Microbeam Anal. Soc., Microsc. Soc. Can. 18 (1), 35-49.

Dejana, E., 2010. The role of wnt signaling in physiological and pathological angiogenesis. Circ. Res. 107 (8), 943-952.
Dijksterhuis, J.P., Petersen, J., Schulte, G., 2014. WNT/Frizzled signalling: receptorligand selectivity with focus on FZD-G protein signalling and its physiological relevance: IUPHAR Review 3. Br. J. Pharmacol. 171 (5), 1195-1209.

Duan, J., Gherghe, C., Liu, D., Hamlett, E., Srikantha, L., Rodgers, L., et al., 2012. Wnt1/ betacatenin injury response activates the epicardium and cardiac fibroblasts to promote cardiac repair. EMBO J. 31 (2), 429-442.

Ezan, J., Leroux, L., Barandon, L., Dufourcq, P., Jaspard, B., Moreau, C., et al., 2004. FrzA/sFRP-1, a secreted antagonist of the Wnt-Frizzled pathway, controls vascular cell proliferation in vitro and in vivo. Cardiovasc. Res. 63 (4), 731-738.

Freedman, D.S., Newman 3rd, W.P., Tracy, R.E., Voors, A.E., Srinivasan, S.R., Webber, L.S., et al., 1988. Black-white differences in aortic fatty streaks in adolescence and early adulthood: the Bogalusa Heart Study. Circulation 77 (4), 856-864.

Galasso, G., Schiekofer, S., D’Anna, C., Gioia, G.D., Piccolo, R., Niglio, T., et al., 2014. No-reflow phenomenon: pathophysiology, diagnosis, prevention, and treatment. A review of the current literature and future perspectives. Angiology 65 (3), 180-189.

Gessert, S., Kuhl, M., 2010. The multiple phases and faces of wnt signaling during cardiac differentiation and development. Circ. Res. 107 (2), 186-199.

Goliasch, G., Wiesbauer, F., Kastl, S.P., Katsaros, K.M., Blessberger, H., Maurer, G. et al., 2012. Premature myocardial infarction is associated with low serum levels of Wnt-1. Atherosclerosis 222 (1), 251-256.

Goodwin, A.M., Kitajewski, J., D’Amore, P.A., 2007. Wnt1 and Wnt5a affect endothelial proliferation and capillary length; Wnt2 does not. Growth Factors 25 (1), 25-32.

Goodwin, A.M., Sullivan, K.M., D’Amore, P.A., 2006. Cultured endothelial cells display endogenous activation of the canonical Wnt signaling pathway and express multiple ligands, receptors, and secreted modulators of Wnt signaling. Dev. Dyn.: Off. publ. Am. Assoc. Anat. 235 (11), 3110-3120.

Hahn, J.Y., Cho, H.J., Bae, J.W., Yuk, H.S., Kim, K.I., Park, K.W., et al., 2006. Betacatenin overexpression reduces myocardial infarct size through differential effects on cardiomyocytes and cardiac fibroblasts. J. Biol. Chem. 281 (41), 30979-30989.

He, W., Zhang, L., Ni, A., Zhang, Z., Mirotsou, M., Mao, L., et al., 2010. Exogenously administered secreted frizzled related protein 2 (Sfrp2) reduces fibrosis and improves cardiac function in a rat model of myocardial infarction. Proc. Natl. Acad. Sci. USA 107 (49), 21110-21115.

Heusch, G., Libby, P., Gersh, B., Yellon, D., Bohm, M., Lopaschuk, G., et al., 2014. Cardiovascular remodelling in coronary artery disease and heart failure. Lancet 383 (9932), 1933-1943.

Janda, C.Y., Waghray, D., Levin, A.M., Thomas, C., Garcia, K.C., 2012. Structural basis of Wnt recognition by Frizzled. Science 337 (6090), 59-64.

Juhaszova, M., Zorov, D.B., Kim, S.H., Pepe, S., Fu, Q., Fishbein, K.W., et al., 2004. Glycogen synthase kinase-3beta mediates convergence of protection signaling to inhibit the mitochondrial permeability transition pore. J. Clin. Investig. 113 (11), 1535-1549.

Kikuchi, A., 2000. Regulation of beta-catenin signaling in the Wnt pathway. Biochem. Biophys. Res. Commun. 268 (2), 243-248.

Kim, J., Kim, J., Kim, D.W., Ha, Y., Ihm, M.H., Kim, H., et al., 2010. Wnt5a induces endothelial inflammation via beta-catenin-independent signaling. J. Immunol. 185 (2), 1274-1282.

Kim, K.I., Park, K.U., Chun, E.J., Choi, S.I., Cho, Y.S., Youn, T.J., et al., 2011. A novel biomarker of coronary atherosclerosis: serum DKK1 concentration correlates with coronary artery calcification and atherosclerotic plaques. J. Kor. Med. Sci. 26 (9), 1178-1184.

Kobayashi, K., Luo, M., Zhang, Y., Wilkes, D.C., Ge, G., Grieskamp, T., et al., 2009. Secreted Frizzled-related protein 2 is a procollagen $C$ proteinase enhancer with a role in fibrosis associated with myocardial infarction. Nat. Cell Biol. 11 (1), $46-55$.

Laeremans, H., Hackeng, T.M., van Zandvoort, M.A., Thijssen, V.L., Janssen, B.J., Ottenheijm, H.C., et al., 2011. Blocking of frizzled signaling with a homologous peptide fragment of wnt3a/wnt5a reduces infarct expansion and prevents the development of heart failure after myocardial infarction. Circulation 124 (15), $1626-1635$.

Liao, J.K., Laufs, U., 2005. Pleiotropic effects of statins. Annu. Rev. Pharmacol. Toxicol. 45, 89-118.

Libby, P., 2002. Inflammation in atherosclerosis. Nature 420 (6917), 868-874.

Maas, A.H., van der Schouw, Y.T., Regitz-Zagrosek, V., Swahn, E., Appelman, Y.E., Pasterkamp, G., et al., 2011. Red alert for women's heart: the urgent need for more research and knowledge on cardiovascular disease in women: proceedings of the workshop held in Brussels on gender differences in cardiovascular disease, 29 September 2010. Eur. Heart J. 32 (11), 1362-1368.

Magoori, K., Kang, M.J., Ito, M.R., Kakuuchi, H., Ioka, R.X., Kamataki, A., et al., 2003. Severe hypercholesterolemia, impaired fat tolerance, and advanced atherosclerosis in mice lacking both low density lipoprotein receptor-related protein 5 and apolipoprotein E. J. Biol. Chem. 278 (13), 11331-11336.

Malgor, R., Bhatt, P.M., Connolly, B.A., Jacoby, D.L., Feldmann, K.J., Silver, M.J., et al., 2014. Wnt5a, TLR2 and TLR4 are elevated in advanced human atherosclerotic lesions. Inflamm. Res 63 (4), 277-285.

Mani, A., Radhakrishnan, J., Wang, H., Mani, M.A., Nelson-Williams, C., Carew, K.S., et al., 2007. LRP6 mutation in a family with early coronary disease and metabolic risk factors. Science 315 (5816), 1278-1282.

Marchand, A., Atassi, F., Gaaya, A., Leprince, P., Le Feuvre, C., Soubrier, F., et al., 2011. The Wnt/beta-catenin pathway is activated during advanced arterial aging in humans. Aging Cell 10 (2), 220-232.

Marinou, K., Christodoulides, C., Antoniades, C., Koutsilieris, M., 2012. Wnt signaling in cardiovascular physiology. Trends Endocrinol. Metab. 23 (12), 628-636. 
Masckauchan, T.N., Agalliu, D., Vorontchikhina, M., Ahn, A., Parmalee, N.L., Li, C.M., et al., 2006. Wnt5a signaling induces proliferation and survival of endothelial cells in vitro and expression of MMP-1 and Tie-2. Mol. Biol. Cell 17 (12) 5163-5172.

Mastri, M., Shah, Z., Hsieh, K., Wang, X., Wooldridge, B., Martin, S., et al., 2014. Secreted Frizzled-related protein 2 as a target in antifibrotic therapeutic intervention. Am. J. Physiol. Cell Physiol. 306 (6), C531-C539.

Mastroiacovo, F., Busceti, C.L., Biagioni, F., Moyanova, S.G., Meisler, M.H., Battaglia, G., et al., 2009. Induction of the Wnt antagonist, Dickkopf-1, contributes to the development of neuronal death in models of brain focal ischemia. J. Cereb. Blood Flow Metab. 29 (2), 264-276.

Matsushima, K., Suyama, T., Takenaka, C., Nishishita, N., Ikeda, K., Ikada, Y., et al., 2010. Secreted frizzled related protein 4 reduces fibrosis scar size and ameliorates cardiac function after ischemic injury. Tissue Eng. Part A 16 (11), 3329-3341.

McNamara, D.J., 2000. Dietary cholesterol and atherosclerosis. Biochim. Biophys. Acta 1529 (1-3), 310-320.

Miller, J.R., 2002. The Wnts. Genome Biol. 3 (1), REVIEWS3001.

Min, J.K., Park, H., Choi, H.J., Kim, Y., Pyun, B.J., Agrawal, V., et al., 2011. The WNT antagonist Dickkopf2 promotes angiogenesis in rodent and human endothelial cells. J. Clin. Investig. 121 (5), 1882-1893.

Mirotsou, M., Zhang, Z., Deb, A., Zhang, L., Gnecchi, M., Noiseux, N., et al., 2007. Secreted frizzled related protein 2 (Sfrp2) is the key Akt-mesenchymal stem cell-released paracrine factor mediating myocardial survival and repair. Proc. Natl. Acad. Sci. USA 104 (5), 1643-1648.

Oerlemans, M.I., Goumans, M.J., van Middelaar, B., Clevers, H., Doevendans, P.A., Sluijter, J.P., 2010. Active Wnt signaling in response to cardiac injury. Basic Res. Cardiol. 105 (5), 631-641.

Oikonomopoulos, A., Sereti, K.I., Conyers, F., Bauer, M., Liao, A., Guan, J., et al., 2011. Wnt signaling exerts an antiproliferative effect on adult cardiac progenitor cells through IGFBP3. Circ. Res. 109 (12), 1363-1374.

Ostrom, R.S., 2014. A new molecular target for blunting organ fibrosis. Focus on "Secreted Frizzled-related protein 2 as a target in antifibrotic therapeutic intervention". Am. J. Physiol. Cell Physiol. 306 (6), C527-C528.

Owens, G.K., Kumar, M.S., Wamhoff, B.R., 2004. Molecular regulation of vascular smooth muscle cell differentiation in development and disease. Physiol. Rev. 84 (3), 767-801.

Pereira, C.P., Bachli, E.B., Schoedon, G., 2009. The wnt pathway: a macrophage effector molecule that triggers inflammation. Curr. Atheroscler. Rep. 11 (3), 236-242.

Perez Castrillon, J.L., San Miguel, A., Vega, G., Abad, L., Andres Domingo, M., Gonzalez Sagredo, M., et al., 2010. Levels of DKK1 in patients with acute myocardial infarction and response to atorvastatin. Int. J. Cardiol. 145 (1), 164-165.

Qin, L., Hu, R., Zhu, N., Yao, H.L., Lei, X.Y., Li, S.X., et al., 2014. The novel role and underlying mechanism of Wnt5a in regulating cellular cholesterol accumulation. Clin. Exp. Pharmacol. Physiol 41 (9), 671-678.

Quasnichka, H., Slater, S.C., Beeching, C.A., Boehm, M., Sala-Newby, G.B., George, S.J., 2006. Regulation of smooth muscle cell proliferation by beta-catenin/T-cell factor signaling involves modulation of cyclin D1 and p21 expression. Circ. Res. 99 (12), 1329-1337.

Reddy, V.S., Valente, A.J., Delafontaine, P., Chandrasekar, B., 2011. Interleukin-18/ WNT1-inducible signaling pathway protein-1 signaling mediates human saphenous vein smooth muscle cell proliferation. J. Cell. Physiol. 226 (12), 3303-3315.

Saraswati, S., Alfaro, M.P., Thorne, C.A., Atkinson, J., Lee, E., Young, P.P., 2010. Pyrvinium, a potent small molecule Wnt inhibitor, promotes wound repair and post-MI cardiac remodeling. PloS One 5 (11), e15521.

Sarzani, R., Salvi, F., Bordicchia, M., Guerra, F., Battistoni, I., Pagliariccio, G., et al., 2011. Carotid artery atherosclerosis in hypertensive patients with a functional LDL receptor-related protein 6 gene variant. Nutr. Metab. Cardiovasc. Dis. 21 (2), $150-156$.

Sasaki, T., Hwang, H., Nguyen, C., Kloner, R.A., Kahn, M., 2013. The small molecule Wnt signaling modulator ICG-001 improves contractile function in chronically infarcted rat myocardium. PloS One 8 (9), e75010.

Schaale, K., Neumann, J., Schneider, D., Ehlers, S., Reiling, N., 2011. Wnt signaling in macrophages: augmenting and inhibiting mycobacteria-induced inflammatory responses. Eur. J. Cell Biol. 90 (6-7), 553-559.

Schulte, G., Bryja, V., 2007. The Frizzled family of unconventional G-protein- coupled receptors. Trends Pharmacol. Sci. 28 (10), 518-525.

Seifert-Held, T., Pekar, T., Gattringer, T., Simmet, N.E., Scharnagl, H., Stojakovic, T. et al., 2011. Circulating Dickkopf-1 in acute ischemic stroke and clinically stable cerebrovascular disease. Atherosclerosis 218 (1), 233-237.

Shinde, A.V., Frangogiannis, N.G., 2014. Fibroblasts in myocardial infarction: a role in inflammation and repair. J. Mol. Cell. Cardiol. 70, 74-82.

Slater, S.C., Koutsouki, E., Jackson, C.L., Bush, R.C., Angelini, G.D., Newby, A.C., et al., 2004. R-cadherin:beta-catenin complex and its association with vascular smooth muscle cell proliferation. Arterioscler. Thromb. Vasc. Biol. 24 (7), 1204-1210.

Sun, F.L., Wang, W., Zuo, W., Xue, J.L., Xu, J.D., Ai, H.X., et al., 2014. Promoting neurogenesis via Wnt/beta-catenin signaling pathway accounts for the neurorestorative effects of morroniside against cerebral ischemia injury. Eur. J. Pharmacol. 738, 214-221.

Sun, Y., Kiani, M.F., Postlethwaite, A.E., Weber, K.T., 2002. Infarct scar as living tissue. Basic Res. Cardiol. 97 (5), 343-347.

Surana, R., Sikka, S., Cai, W., Shin, E.M., Warrier, S.R., Tan, H.J., et al., 2014. Secreted frizzled related proteins: implications in cancers. Biochim. Biophys. Acta 1845 (1), 53-65.

Tsaousi, A., Mill, C., George, S.J., 2011a. The Wnt pathways in vascular disease: lessons from vascular development. Curr. Opin. Lipidol. 22 (5), 350-357.

Tsaousi, A., Williams, H., Lyon, C.A., Taylor, V., Swain, A., Johnson, J.L., et al., 2011b. Wnt4/beta-catenin signaling induces VSMC proliferation and is associated with intimal thickening. Circ. Res. 108 (4), 427-436.

Ueland, T., Otterdal, K., Lekva, T., Halvorsen, B., Gabrielsen, A., Sandberg, W.J., et al., 2009. Dickkopf-1 enhances inflammatory interaction between platelets and endothelial cells and shows increased expression in atherosclerosis. Arterioscler. Thromb. Vasc. Biol. 29 (8), 1228-1234.

Uglow, E.B., Slater, S., Sala-Newby, G.B., Aguilera-Garcia, C.M., Angelini, G.D., Newby, A.C., et al., 2003. Dismantling of cadherin-mediated cell-cell contacts modulates smooth muscle cell proliferation. Circ. Res. 92 (12), 1314-1321.

van de Schans, V.A., Smits, J.F., Blankesteijn, W.M., 2008. The Wnt/frizzled pathway in cardiovascular development and disease: friend or foe? Eur. J. Pharmacol. 585 (2-3), 338-345.

van den Borne, S.W., Diez, J., Blankesteijn, W.M., Verjans, J., Hofstra, L., Narula, J., 2010. Myocardial remodeling after infarction: the role of myofibroblasts. Nat. Rev. Cardiol. 7 (1), 30-37.

Vikram, A., Kim, Y.R., Kumar, S., Naqvi, A., Hoffman, T.A., Kumar, A., et al., 2014 Canonical Wnt signaling induces vascular endothelial dysfunction via p66Shcregulated reactive oxygen species. Arterioscler. Thromb. Vasc. Biol. 34 (10), 2301-2309.

Wang, L., Hu, X.B., Zhang, W., Wu, L.D., Liu, Y.S., Hu, B., et al., 2013. Dickkopf-1 as a novel predictor is associated with risk stratification by GRACE risk scores for predictive value in patients with acute coronary syndrome: a retrospective research. PloS One 8 (1), e54731.

Wang, X., Adhikari, N., Li, Q., Hall, J.L., 2004. LDL receptor-related protein LRP6 regulates proliferation and survival through the Wnt cascade in vascular smooth muscle cells. Am. J. Physiol. Heart Circ. Physiol. 287 (6), H2376-H2383.

Wang, X., Xiao, Y., Mou, Y., Zhao, Y., Blankesteijn, W.M., Hall, J.L., 2002. A role for the beta-catenin/T-cell factor signaling cascade in vascular remodeling. Circ. Res. 90 (3), 340-347.

Wang, Y., Li, Y.P., Paulson, C., Shao, J.Z., Zhang, X., Wu, M., et al., 2014. Wnt and the Wnt signaling pathway in bone development and disease. Front. Biosci. (Landmark Ed.) 19, 379-407.

Woulfe, K.C., Gao, E., Lal, H., Harris, D., Fan, Q., Vagnozzi, R., et al., 2010. Glycogen synthase kinase-3beta regulates post-myocardial infarction remodeling and stress-induced cardiomyocyte proliferation in vivo. Circ. Res. 106 (10), 1635-1645.

Wright, M., Aikawa, M., Szeto, W., Papkoff, J., 1999. Identification of a Wnt-responsive signal transduction pathway in primary endothelial cells. Biochem. Biophys. Res. Commun. 263 (2), 384-388.

Zelarayan, LC., Noack, C. Sekkali, B., Kmecova, J., Gehrke, C. Renger, A., et al, 2008 Beta-Catenin downregulation attenuates ischemic cardiac remodeling through enhanced resident precursor cell differentiation. Proc. Natl. Acad. Sci. USA 105 (50), 19762-19767. 